\title{
Failure of 2-Pyridinecarboxylic Acid, an Inhibitor of 1-Aminocyclopropane-1- carboxylate Oxidase, as a Universal Flower Care Agent to Extend the Vase Life of Cut Carnation Flowers
}

\author{
Shigeru Satoh*, Keiko Makino, Keita Shimada and Yoshihiro Nomura \\ Faculty of Agriculture, Ryukoku University, Otsu 520-2194, Japan
}

2-Pyridinecarboxylic acid (2-PCA) acts as an inhibitor of ethylene biosynthesis in Arabidopsis thaliana by binding to the active site of 1-aminocyclopropane-1-carboxylate oxidase. In this study, we examined the action of 2-PCA in comparison with the action of 3-PCA, a recently discovered stimulator of flower opening, in cut flowers of the spray-type carnation cultivars, 'Light Pink Barbara (LPB)', 'Carnet', 'Collin', and 'Zulia'. With 'LPB' flowers, 2-PCA at $0.5-5 \mathrm{mM}$ did not prolong the vase life, whereas 3-PCA at $5 \mathrm{mM}$ did so. With the other three cultivars, 3-PCA generally promoted flower opening of all the cultivars. On the other hand, the action of 2-PCA on flower opening and senescence varied with the carnation cultivar and time of harvest, resulting in a shortened, unchanged or lengthened vase life of the flowers. 2-PCA also caused severe bending of flower stems in all cultivars, which lowered the display value of the flowers. The present results showed that 2PCA is not likely to be a useful flower care agent in carnation flowers.

Key Words: carnation cultivars, Dianthus caryophyllus, flower senescence, pyridinecarboxylic acids, stem bending.

\section{Introduction}

Ethylene plays an essential role in the regulation of carnation flower senescence; i.e., during senescence of the flowers, a climacteric increase in ethylene production occurs, and the evolved ethylene induces in-rolling of petals, resulting in wilting of whole flowers. The effect of ethylene on carnation flower senescence can be diminished by treating the flowers with ethylene biosynthesis inhibitors (Satoh et al., 2014). Treatment with these inhibitors prolongs the vase life of cut carnation flowers.

Pyridinedicarboxylic acid (PDCA) isomers extend the vase life of spray-type carnation flowers by accelerating flower opening and retarding senescence (Satoh et al., 2014; Satoh and Nomura, 2016). Among PDCA isomers, 2,3-PDCA and 2,4-PDCA were shown to be equally and highly effective (Sugiyama and Satoh, 2015). Further analysis on the promotion of flower

Received; October 10, 2019. Accepted; November 18, 2019.

First Published Online in J-STAGE on January 10, 2020.

This study was supported financially by a Grant-in-Aid (16K07604 to S. Satoh) for Scientific Research from the Japan Society for the Promotion of Science.

* Corresponding author (E-mail: ssatoh@agr.ryukoku.ac.jp). opening in carnation flowers revealed that a carboxyl group substituted on position 3 of the pyridine ring is necessary to exert its activity on flower opening, and 3pyridinecarboxylic acid (3-PCA) and its derivative, 3PCA amide, most effectively promoted flower opening (Satoh and Nomura, 2019). Unfortunately, however, the mechanism for promotion of flower opening by these PCA and PDCA analogs remains unknown.

On the other hand, it was shown that extension of the vase life of cut carnation flowers by 2,4-PDCA is partly due to reduced ethylene production (Vlad et al., 2010; Satoh et al., 2014). 2,4-PDCA was shown to inhibit the in vitro activity of 1-aminocyclopropane-1-carboxylate (ACC) oxidase, which catalyzes the final step of ethylene biosynthesis, using an enzyme prepared from tomato pericarp tissues (Fragkostefanakis et al., 2013) and a recombinant enzyme produced in Escherichia coli cells from the carnation ACC oxidase gene, DcACOI cDNA (Satoh et al., 2014). Vlad et al. (2010) proposed that 2,4-PDCA inhibited ACC oxidase by competing with ascorbate, a co-substrate of the enzyme action.

Independently of these studies, Sun et al. (2017) identified 2-PCA, a simple analog of 2,4-PDCA, as an inhibitor of ethylene biosynthesis in Arabidopsis thaliana, which suppressed the activity of ACC 
oxidase. By X-ray crystallographic analyses of Arabidopsis ACC oxidase 2 in complex with 2-PCA, they showed that 2-PCA binds to the active site of ACC oxidase, preventing the enzyme from interacting with its natural substrates. They reported 2-PCA to be a promising regulator of plant metabolism, in particular ethylene biosynthesis, for use as an agent to regulate ethylene-related processes like flower senescence and fruit ripening. Since 2-PCA is a derivative of pyridine, an aromatic compound, there may be health concerns if it is used at high concentrations to regulate fruit ripening. However, it may be useful to regulate senescence of flowers which are used for non-edible and ornamental purposes.

Satoh and Nomura (2019) recently showed that 2PCA treatment did not extend the vase life of cut flowers of 'Light Pink Barbara (LPB)' carnations, but in fact shortened the vase life of the flowers. Cut 'LPB' flowers were shown to produce ethylene during flower senescence (Satoh et al., 2014). These findings do not support the above-mentioned proposal that 2-PCA is a potent retardant of ethylene-related senescence in flowers. Satoh and Nomura (2019) used 2-PCA at $5 \mathrm{mM}$ to compare its effects with those of the isomers of PDCAs and PCAs, which were previously used effectively at $5 \mathrm{mM}$. 2-PCA acts as a general inhibitor by chelating metal ions such as $\mathrm{Zn}^{2+}, \mathrm{Fe}^{2+}$, and $\mathrm{Cu}^{2+}$ (Fernandez-Pol and Johnson, 1977). 2-PCA at $5 \mathrm{mM}$ may act as a general inhibitor by chelating some metal ions, and disturbing enzyme action responsible for maintaining cell metabolism; it had no, or little, effect on flower senescence in the experiment of Satoh and Nomura (2019). We assumed that 2-PCA may act as a specific inhibitor of ethylene production when used at lower concentrations. This idea encouraged us to examine the action of 2-PCA at concentrations lower than $5 \mathrm{mM}$. Furthermore, it was interesting to investigate whether 2-PCA would fail to extend the vase life of carnation cultivar flowers other than 'LPB'.

In the present study, to further evaluate the potential of 2-PCA as a flower care agent in carnation flowers, we examined its effects in comparison with those of 3PCA on flower opening and senescence of cut flowers by focusing on low concentrations of 2-PCA and different cultivars other than 'LPB'.

\section{Materials and Methods}

\section{Carnation flowers}

Four carnation cultivars, Dianthus caryophyllus L. 'Light Pink Barbara (LPB)', 'Carnet', 'Collin', and 'Zulia', which have spray-type carnation flowers, were used. 'LPB' carnation flowers were harvested with 70$\mathrm{cm}$ long stems at the nursery of a commercial grower in Nagano Prefecture, Japan. 'Carnet', 'Collin', and 'Zulia' cultivar flowers were harvested with $60-\mathrm{cm}$ long stems at the nursery of a commercial grower in Miyagi Prefecture, Japan. The carnation flowers were harvested in the afternoon, immediately placed in plastic containers with their cut stalk ends in tap water, and dispatched the next morning to the Faculty of Agriculture of Ryukoku University, Otsu, Shiga Prefecture, with no water supplied during transportation. The flowers were not treated with any flower preservatives, such as sodium silverthiosulfate anionic complex (STS), after harvest.

When they arrived at our laboratory the next day, the flowers were at flower opening stage Os 1 , when petals have just emerged from almost all buds (Harada et al., 2010). The flowers were placed in plastic buckets with their cut stalk ends in tap water under continuous light from white fluorescent lamps $\left(14 \mu \mathrm{mol} \cdot \mathrm{m}^{-2} \cdot \mathrm{s}^{-1}\right.$ PPFD $)$ at $23-25^{\circ} \mathrm{C}$ and $40-60 \%$ relative humidity, until the start of experiments.

Effects of 2-PCA at 0.5-5 $\mathrm{mM}$ and 3-PCA at $5 \mathrm{mM}$ on flower opening and senescence of 'Light Pink Barbara' carnation flowers

This experiment was conducted with flowers (Flower Lot 1) harvested in the middle of September, 2019, followed by treatment and observation conducted from September 17 to October 7, 2019. Three samples (bunches) of five or six flower stalks (trimmed to $50 \mathrm{~cm}$ ), each having five or six flower buds ( 25 buds in total per sample), were put in 0.9-L glass jars with their stalk ends in $300 \mathrm{~mL}$ of test solutions (one sample per glass jar) for $24 \mathrm{hr}$, and kept in pure water $(>15 \mathrm{M} \Omega)$ thereafter. Test solutions were water (control), 2-PCA at $0.5,1,2$, or $5 \mathrm{mM}$ or 3-PCA at $5 \mathrm{mM}$. 2-PCA and 3PCA were purchased from Wako Pure Chemical Industries, Ltd. (Osaka, Japan). The stock solution of $100 \mathrm{mM}$ of each chemical was adjusted to $\mathrm{pH} 7$ with $1 \mathrm{~N} \mathrm{NaOH}$, and test solutions were prepared by dilution with pure water. The flowers were left for 22 days under continuous light from white fluorescent lamps $\left(14 \mu \mathrm{mol} \cdot \mathrm{m}^{-2} \cdot \mathrm{s}^{-1} \mathrm{PPFD}\right)$ at $23-25^{\circ} \mathrm{C}$ and $40-60 \%$ relative humidity.

During the flower opening and senescence periods, the vase water was replenished with pure water once a week. Fully-open and non-sienescent (not wilted or turgid) flowers (FONS flowers), at flower opening stages Os 6 to Ss 2 (Harada et al., 2010; Morita et al., 2011), were counted daily and the percentage of these flowers from the total number of initial flower buds per sample was calculated. Data are presented as the percentages of FONS flowers during experiments. Flower samples having more than $30 \%$ FONS flowers were regarded as having display value as explained previously (Satoh et al., 2014; Sugiyama and Satoh, 2015).

The vase life of cut flowers is shown by the number of days for which the flowers had display value. The time to flower opening was determined as the number of days from the start of the experiment to the time when the percentage of FONS flowers reached 30\% (Sugiyama and Satoh, 2015). Data are shown by the 
mean of three samples.

In addition to the changes in flowering profiles in response to 2-PCA or 3-PCA treatment shown in Figure 1, we summarized in Table 1 the time to flower opening and the vase life of flowers, which were determined from flowering profiles. Values for the time to flower opening and the vase life of flowers are shown by the mean $\pm \mathrm{SE}$, calculated from three replicated samples for each cultivar.

Effects of 2-PCA and 3-PCA, both at $5 \mathrm{mM}$, on flower opening and senescence of 'Carnet', 'Collin', and 'Zulia' flowers

These experiments were repeated two times with carnation flowers (Flower Lot 2) harvested at the end of January, 2019, followed by treatment and observation from January 31, 2019 to February 25, 2019, and those

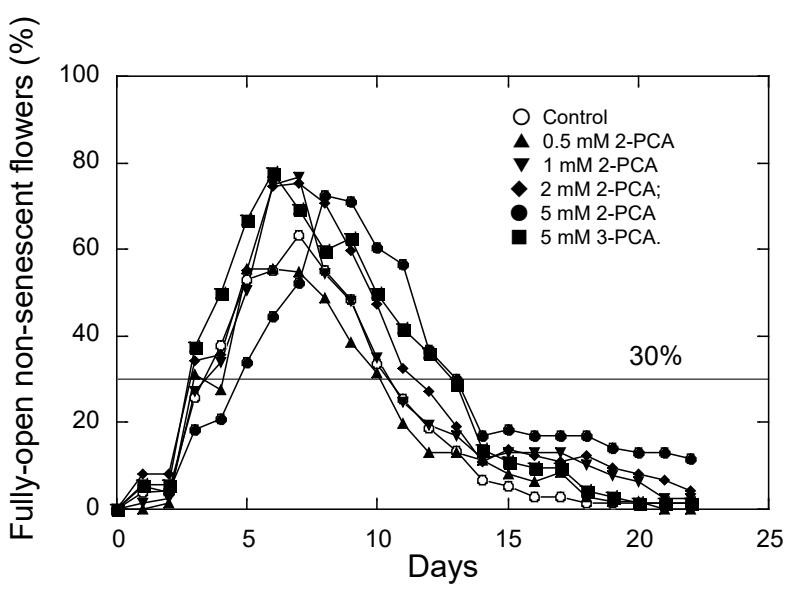

Fig. 1. Changes in the percentage of fully-open and non-senescent cut flowers of the 'Light Pink Barbara' cultivar pre-treated with 2-PCA at $0.5-5 \mathrm{mM}$ or $3-\mathrm{PCA}$ at $5 \mathrm{mM}$. Flowers were treated without and with 2-PCA at $0.5-5 \mathrm{mM}$, or 3-PCA at $5 \mathrm{mM}$ for $24 \mathrm{hr}$ then kept in water for 22 days at $23-25^{\circ} \mathrm{C}$. Data show the mean of three replicated samples, each with five or six flower stalks with 25 flower buds in total. The threshold value to determine the time to flower opening and fully-open and nonsenescent flowers was set at $30 \%$ as explained by Sugiyama and Satoh (2015)

Table 1. Comparison of time to flower opening and vase life in 'Light Pink Barbara' flowers pretreated without or with 2PCA at different concentrations or $5 \mathrm{mM} 3-\mathrm{PCA}$.

\begin{tabular}{lcc}
\hline \hline \multicolumn{1}{c}{ Treatment } & $\begin{array}{c}\text { Time to flower } \\
\text { opening (days) }\end{array}$ & Vase life (days) \\
\hline $\mathrm{H}_{2} \mathrm{O}$ (Control) & $3.5 \pm 0.6$ & $6.8 \pm 0.2$ \\
$0.5 \mathrm{mM}$ 2-PCA & $3.3 \pm 0.7$ & $6.7 \pm 0.5$ \\
$1 \mathrm{mM} 2-\mathrm{PCA}$ & $3.4 \pm 0.4$ & $7.3 \pm 0.6$ \\
$2 \mathrm{mM}$ 2-PCA & $3.3 \pm 0.9$ & $8.0 \pm 1.2$ \\
$5 \mathrm{mM}$ 2-PCA & $4.8 \pm 0.5$ & $8.0 \pm 0.9$ \\
$5 \mathrm{mM} 3-\mathrm{PCA}$ & $2.8 \pm 0.2$ & $9.3^{*} \pm 1.2$ \\
\hline
\end{tabular}

* shows significant difference from the control by Dunnett's multiple range test $(P<0.05)$
(Flower Lot 3) harvested in the middle of April 2019, followed by treatment and observation from April 11, 2019 to May 6, 2019.

Treatment and observation of carnation flowers were similar to those described in the previous section with the exceptions described below. In the experiment with Flower Lot 2, flower stalks were trimmed to $40 \mathrm{~cm}$, and in the experiment with Flower Lot 3, about 30 buds in total were used per sample (bunch). Flower samples were treated without and with 2-PCA or 3-PCA at $5 \mathrm{mM}$ for $24 \mathrm{hr}$, and kept in pure water thereafter. The three cultivars in Flower Lot 2 were named Carnet-1, Collin-1, and Zulia-1, respectively, and those of Flower Lot 3 Carnet-2, Collin-2, and Zulia-2, respectively, as shown in Figure 2 and Table 2. The flowers were photographed with flower samples of Flower Lot 3 on day 13 when the severe stem bending due to chemical treatment peaked.

\section{Statistical analyses}

Statistical analyses were performed by Dunnett's multiple range test using an online statistical program MEPHAS (http://www.gen-info.osaka-u.ac.jp/MEPHAS/).

\section{Results and Discussion}

Effects of 2-PCA at different concentrations on flower opening and senescence of 'Light Pink Barbara' carnation flowers

Figure 1 shows the flower opening profile of 'LPB' flowers treated without and with 2-PCA at $0.5-5 \mathrm{mM}$. At first glance, flower opening profiles showed that 3PCA at $5 \mathrm{mM}$ promoted flower opening, whereas 2PCA at $5 \mathrm{mM}$ delayed it. 2-PCA at $0.5-2 \mathrm{mM}$ did not affect the flower opening profile. Interestingly, a small number of FONS flowers remained fully-open and nonsenescent until the latest stage (later than 15 days in the experiment with flowers treated with 1 and $2 \mathrm{mM} 2$ PCA). This phenomenon was thought to be caused by the action of 2-PCA to inhibit ethylene production as observed previously with 2,4-PDCA treatment (Satoh et al., 2014).

Table 1 summarizes the time to flower opening and the vase life, which were determined from the flower opening profile in Figure 1. The control flowers had a time to flower opening of 3.5 days and a vase life of 6.8 days. 2-PCA at $5 \mathrm{mM}$ delayed the time to flower opening by 1.3 days, although the delay was not significantly different from the control. 2-PCA at $0.5-2 \mathrm{mM}$ did not affect the time to flower opening. On the other hand, 2-PCA tended to gradually extend the vase life as its concentration increased, attaining eight days at 2 and $5 \mathrm{mM}$, although again there was no significant difference from the control. The present findings showed that 2-PCA at $0.5-5 \mathrm{mM}$ did not prolong the vase life of 'LPB' carnations, and slightly delayed the flower opening at $5 \mathrm{mM}$. 3-PCA at $5 \mathrm{mM}$ tended to shorten the time to flower opening to 2.8 days, and significantly extend- 


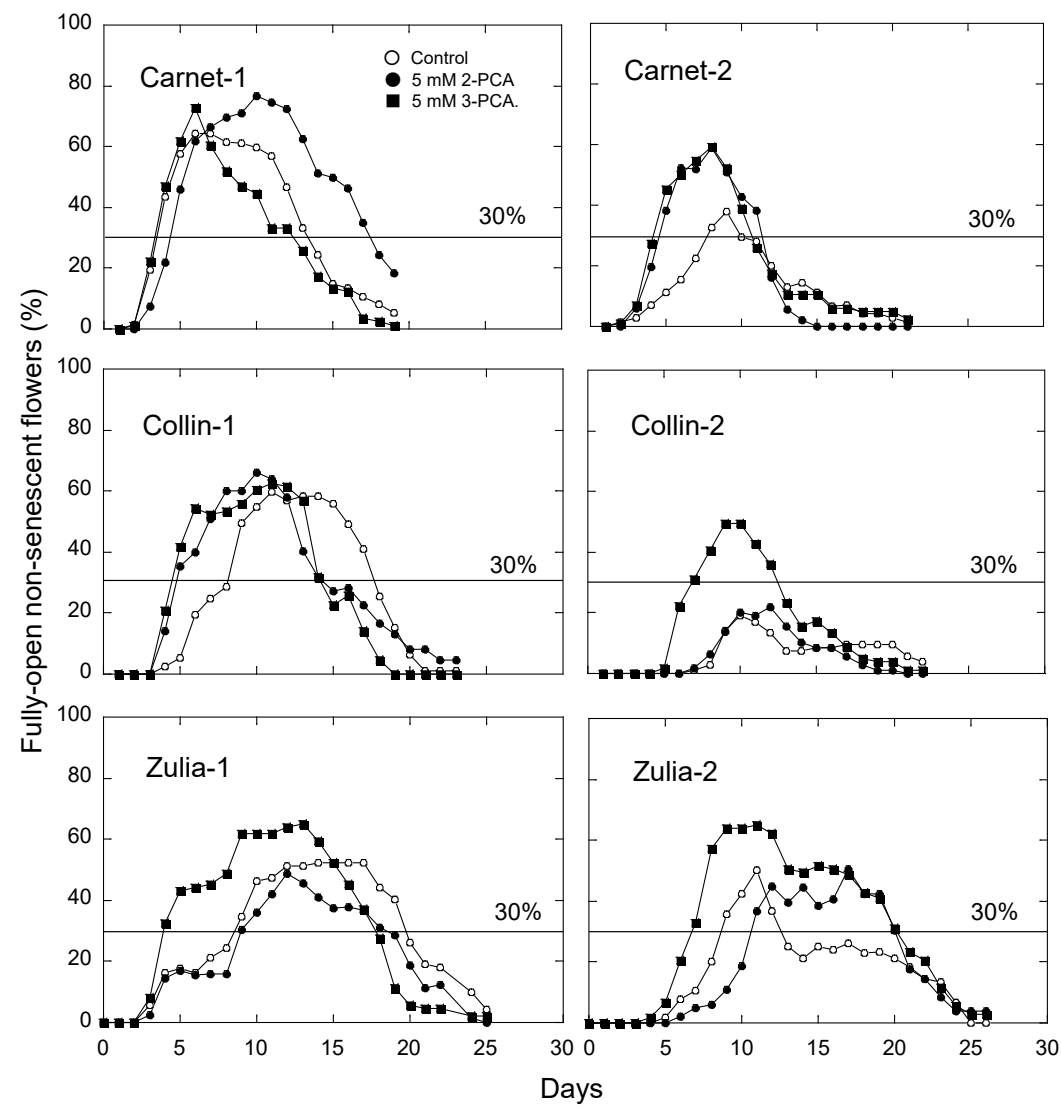

Fig. 2. Changes in the percentage of fully-open and non-senescent cut flowers of the 'Carnet', 'Collin', and 'Zulia' cultivars treated with 2-PCA or 3-PCA. Experiments with flowers harvested at the end of January, 2019 were named Carnet-1, Collin-1, and Zulia-1, and those with flowers harvested in the middle of April, 2019 were named Carnet-2, Collin-2, and Zulia-2. Flowers were treated with or without 2-PCA and 3PCA at $5 \mathrm{mM}$ for $24 \mathrm{hr}$ then kept in water for 24 days at $23-25^{\circ} \mathrm{C}$. Observation of flowering profiles and data treatment were similar to those described in Figure 1 .

Table 2. Comparison of time to flower opening and vase life in flowers of carnation cultivars treated without or with 2-PCA or 3-PCA, both at $5 \mathrm{mM}$.

\begin{tabular}{|c|c|c|c|c|c|c|c|}
\hline \multirow{2}{*}{ Exp. No. } & \multirow{2}{*}{ Cultivar } & \multicolumn{3}{|c|}{ Time to flower opening (days) } & \multicolumn{3}{|c|}{ Vase life (days) } \\
\hline & & Control & 2-PCA & 3-PCA & Control & 2-PCA & 3-PCA \\
\hline \multirow[t]{3}{*}{1} & Carnet & $3.5 \pm 0.3$ & $4.3^{*} \pm 0.3$ & $3.2 \pm 0.1$ & $10.4 \pm 2.3$ & $12.7 \pm 2.3$ & $9.3 \pm 2.6$ \\
\hline & Collin & $7.4 \pm 0.8$ & $4.7 * \pm 0.3$ & $4.2 * \pm 0.7$ & $10.4 \pm 1.0$ & $10.4 \pm 1.9$ & $10.6 \pm 1.0$ \\
\hline & Zulia & $9.6 \pm 0.3$ & $6.0 \pm 4.3$ & $4.8 * \pm 0.2$ & $11.8 \pm 1.7$ & $7.1 \pm 5.6$ & $14.2 \pm 1.0$ \\
\hline \multirow[t]{3}{*}{2} & Carnet & $7.3 \pm 0.3$ & $4.7^{*} \pm 0.3$ & $4.2 * \pm 0.4$ & $3.5 \pm 1.0$ & $6.5^{*} \pm 0.4$ & $6.1 \pm 0.9$ \\
\hline & Collin & - & - & $6.0 \pm 0.3$ & - & - & $5.6 \pm 0.9$ \\
\hline & Zulia & $8.9 \pm 1.7$ & $10.8^{*} \pm 0.2$ & $6.8^{*} \pm 0.2$ & $3.7 \pm 1.7$ & $9.2 * \pm 0.2$ & $13.0 * \pm 2.1$ \\
\hline
\end{tabular}

Data for Exp. 1 were from the Carnet-1, Collin-1, and Zulia-1 experiments, and those for Exp. 2 from the Carnet-2, Collin-2, and Zulia-2 experiments shown in Figure 2.

* shows significant difference from the control by Dunnett's multiple range test $(P<0.05)$.

— shows 'not-determined'.

ed the vase life to 9.3 days. Promotion of flower opening and extension of vase life by 3-PCA treatment agreed with the previous findings (Satoh and Nomura, 2019). The present results showed that 2-PCA at less than $5 \mathrm{mM}$ did not extend the vase life of 'LPB' flowers, and did not support our initial hypothesis.

Although Sun et al. (2017) reported that 2-PCA could strongly inhibit the in vitro action of ACC oxi- dase, it exerted no, or little, beneficial effect to extend the vase life of 'LPB' carnation cultivar cut flowers. A similar result was previously demonstrated with another ACC oxidase inhibitor, 1-aminocyclobutane-1carboxylic acid (ACBC). Kosugi et al. (1997) showed that $\mathrm{ACBC}$ powerfully inhibited the in vitro activity of ACC oxidase obtained from senescing carnation petals by competing with ACC, the substrate of the enzyme, 
with a $K_{i}$ of $20-31 \mu \mathrm{M}$. However, ACBC needed a high concentration (ca. $10 \mathrm{mM}$ ) to retard senescence of carnation flowers, probably because of some unknown metabolic pathway of ACBC affecting inactive compounds. The marked discrepancy between the in vitro and in vivo activities of 2-PCA make its practical use impossible.

Effects of 2-PCA and 3-PCA on flower opening and senescence of 'Carnet', 'Collin', and 'Zulia' carnation flowers

Next, we explored the effect of 2-PCA on the vase life of flowers of carnation cultivars other than 'LPB'. Figure 2 shows the changes in the percentages of FONS flowers of 'Carnet', 'Collin', and 'Zulia' cultivars, which were treated without $\left(\mathrm{H}_{2} \mathrm{O}\right.$, control) and with 2PCA or 3-PCA at $5 \mathrm{mM}$ for $24 \mathrm{hr}$, then left in water for 24 days. Table 2 summarizes the time to flower opening and the vase life of flowers obtained from the flowering profiles shown in Figure 2. 2-PCA treatment lengthened the time to flower opening by 0.8 days, as compared with the control, in the Carnet- 1 experiment, but shortened it by 2.6 days in the Carnet-2 experiment as compared with the control. 2-PCA extended the vase life of flowers by 2.3 days in the Carnet-1 experiment (not significantly), and by 3.0 days in the Carnet- 2 experiment. 3-PCA treatment did not change the time to flower opening of the flowers in the Carnet- 1 experiment and shortened it in the Carnet-2 experiment (by 3.1 days). 3-PCA extended the vase life of flowers only in the
Carnet-2 experiment by 2.6 days.

With 'Collin' flowers, 2-PCA shortened the time to flower opening in the Collin-1 experiment by 2.7 days, but did not change the vase life of flowers. Similar to 2PCA treatment, 3-PCA treatment shortened the time to flower opening, but did not affect the vase life. The flower opening ability of the control flowers in the Collin-2 experiment was extremely low, attaining a maximum percentage of FONS flowers of only $20 \%$. We omitted the Collin-2 experiment data, although it should be noted that 3-PCA treatment shortened the time to flower opening and lengthened the vase life as shown in Figure 2 (Collin-2).

With 'Zulia' carnations, 2-PCA treatment caused no significant difference from the control in the time to flower opening in the Zulia-1 experiment, whereas lengthened it by 1.9 days in the Zulia-2 experiment. 2PCA treatment shortened, although not significantly, the vase lives of flowers by 4.7 days in the Zulia-1 experiment, and lengthened it by 5.5 days in the Zulia-2 experiment. 3-PCA shortened the time to flower opening by 4.8 days in the Zulia-1 experiment and by 2.1 days in the Zulia-2 experiment. 3-PCA extended the vase life of flowers by 2.4 days in the Zulia- 1 experiment and did so by 9.3 days in the Zulia- 2 experiment.

Based on the above findings, 3-PCA treatment stimulated flower opening when judged from the time to flower opening and the length of vase life. Acceleration of flower opening by 3-PCA in the cultivars 'Collin' and 'Zulia' was consistent with the previous results
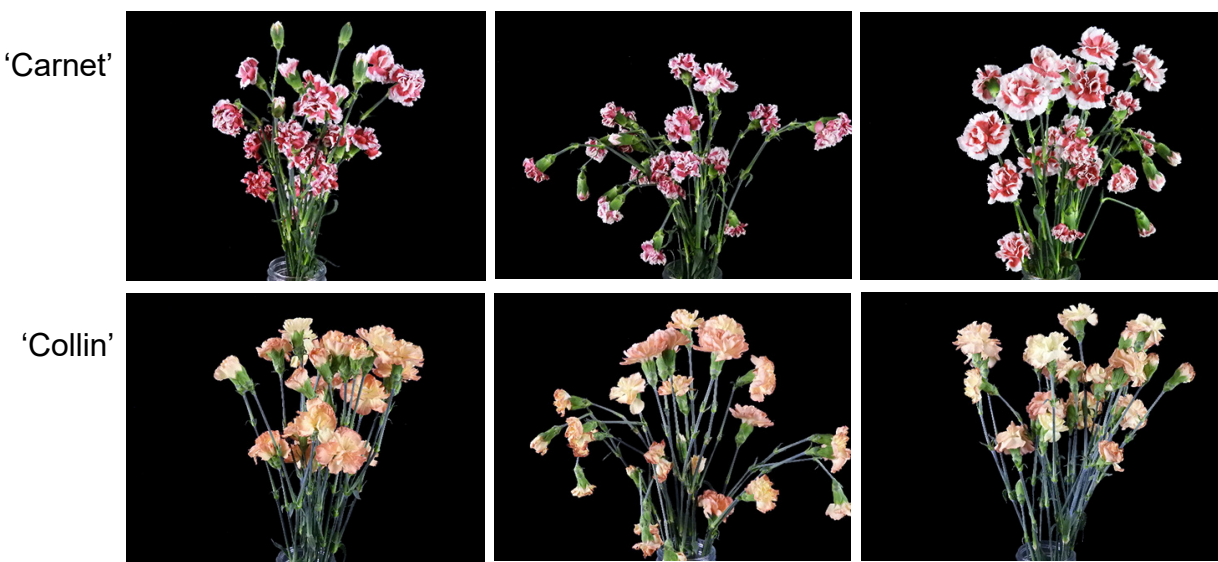

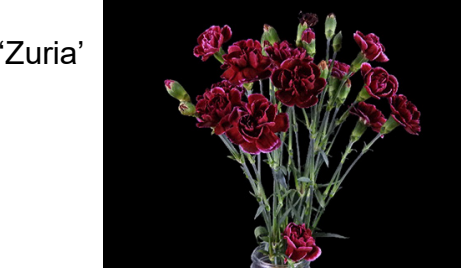

Control

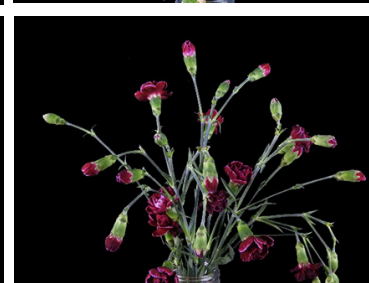

2-PCA

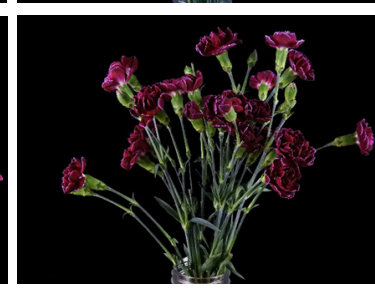

3-PCA

Fig. 3. Stem bending of 'Carnet', 'Collin', and 'Zulia' flowers 13 days after treatment without (control) and with 2-PCA or 3-PCA. Samples of four or five flowers from Flower Lot 2, with 50-cm long stems, for the respective cultivars were treated without (water) and with 2-PCA or 3-PCA at $5 \mathrm{mM}$ for $24 \mathrm{hr}$. Photographs were taken of a typical sample chosen from three samples per cultivar when the stem bending peaked at 13 days after the start of the experiment. 
with 'LPB' carnations (Satoh and Nomura, 2019). On the other hand, the effect of 2-PCA on flower opening varied from stimulation to repression depending on the cultivar and time of flower harvest.

We found that severe stem bending occurred in the flowers treated with $5 \mathrm{mM}$ 2-PCA in flowers of the 'Carnet', 'Collin', and 'Zulia' cultivars (Fig. 3), and 'LPB' and 'Beam Cherry' cultivars in a separate experiment (data not shown). 3-PCA treatment tended to cause slight stem bending in 'Carnet' and 'Zulia' carnations, but not in 'Collin' carnations. 2-PCA has a number of biological functions in mammals, microbes and plant cells. For instance, 2-PCA acts as a specific chelator of metal ions (Fernandez-Pol and Johnson, 1977). In plants, 2-PCA acted as a strong inhibitor of the growth of Lemna paucicostata 151 when tested at $10^{-5}$ to $10^{-3}$ M (Taguchi et al., 1988). 2-PCA may act as a chelator for some metal ions and inhibit enzyme actions responsible for maintaining straight stems in carnation flowers.

In conclusion, the present study revealed that although 2-PCA sometimes accelerates flower opening and extends vase life, its effect varies depending on the cultivar and time of harvest; unfortunately, it causes detrimental stem bending that destroys the display value of cut carnation flowers. These findings suggest that 2-PCA is not a useful universal flower care agent, at least for cut spray-type carnation flowers.

\section{Literature Cited}

Fernandez-Pol, A. and G. S. Johnson. 1977. Selective toxicity induced by picolinic acid in simian virus 40 -tranformed cells in tissue culture. Cancer Res. 37: 4276-4279.

Fragkostefanakis, S., P. Kalaitzis, A. S. Siomos and D. Gerasopoulos. 2013. Pyridine 2,4-dicarboxylate downregulates ethylene production in response to mechanical wounding in excised mature green tomato pericarp discs. J. Plant Growth Regul. 32: 140-147.

Harada, T., Y. Torii, S. Morita, T. Masumura and S. Satoh. 2010.
Differential expression of genes identified by suppression subtractive hybridization in petals of opening carnation flowers. J. Exp. Bot. 61: 2345-2354.

Kosugi, Y., N. Oyamada, S. Satoh, T. Yoshioka, E. Onodera and Y. Yamada. 1997. Inhibition by 1-aminocyclobutane-1carboxylate of the activity of 1-aminocyclopropane-1carboxylate oxidase obtained from senescing petal of carnation (Dianthus caryophyllus L.) flowers. Plant Cell Physiol. 38: 312-318.

Morita, S., Y. Torii, T. Harada, M. Kawarada, R. Onodera and S. Satoh. 2011. Cloning and characterization of a cDNA encoding sucrose synthase associated with flower opening through early senescence in carnation (Dianthus caryophyllus L.). J. Japan. Soc. Hort. Sci. 80: 358-364.

Satoh, S. and Y. Nomura. 2016. Further characterization of the action of pyridinedicarboxylic acids: multifunctional flower care agents for cut flowers of spray-type carnation. J. Appl. Hort. 18: 3-6.

Satoh, S. and Y. Nomura. 2019. Promotion of flower opening of spray-type carnation cut flowers by 3-pyridinecarboxylic acid, a simple analog of pyridinedicarboxylic acids (PDCAs) including 2,3- and 2,4-PDCAs. Hort. J. 88: 293-298.

Satoh, S., Y. Kosugi, S. Sugiyama and I. Ohira. 2014. 2,4Pyridinedicarboxylic acid prolongs the vase life of cut flowers of spray carnations. J. Japan. Soc. Hort. Sci. 83: 72-80.

Sugiyama, S. and S. Satoh. 2015. Pyridinedicarboxylic acids prolong the vase life of cut flowers of spray-type 'Light Pink Barbara' carnation by accelerating flower opening in addition to an already-known action of retarding senescence. Hort. J. 84: 172-177.

Sun, X., Y. Li, W. He, C. Ji, P. Xia, Y. Wang, S. Du, H. Li, N. Raikhel, J. Xiao and H. Guo. 2017. Pyrazinamide and derivatives block ethylene biosynthesis by inhibiting ACC oxidase. Nat. Commun. 8: 15758. DOI: 10.1038/ ncomms 15758 .

Taguchi, H., A. Kashimoto, H. Nishitani, Y. Shimabayashi and K. Iwai. 1988. The effects of pyridine and pyrazine carboxylic acids derivatives on the growth of Lemna pauchicostata 151. Agrc. Biol. Chem. 52: 85-89.

Vlad, F., P. Tiainen, C. Owen, T. Spano, F. B. Daher, F. Oualid, N. O. Senol, D. Vlad, J. Myllyharju and P. Kalaitzis. 2010. Characterization of two carnation petal prolyl 4 hydroxylases. Physiol. Plant. 140: 199-207. 